\title{
EDUTAINMENT AS CONTRIBUTION TO FUTURE EDUCATION OF FOREIGN LANGUAGES IN HIGHER SCHOOLS
}

\author{
Kamo Chilingaryan ${ }^{1 *}$, Ekaterina Zvereva ${ }^{2}$ \\ ${ }^{1}$ Mr. Kamo Chilingaryan, RUDN University, RUSSIA, chili1@yandex.ru \\ ${ }^{2}$ Associate Prof. Ekaterina Zvereva, RUDN University, RUSSIA, frakatr@yandex.ru \\ ${ }^{*}$ Corresponding Author
}

\begin{abstract}
Currently, the social order for higher education is significantly focused on the formation of foreign language communicative competence and the development of communicative skills in foreign languages of a university graduate, allowing the future specialist to carry out effective speech communication in professional and general cultural fields.

The article discusses the features of innovative educational technology, "Edutainment." The genesis of the concept of "edutainment" is presented. The article is devoted to the review of the educational tools of "edutainment," which can be used in the educational process of university education. The works of foreign and domestic researchers, addressing the concept of technology education are analyzed and systematized. A brief chronological note is given on the emergence and establishment of "edutainment" abroad and in Russian didactics. The analysis and generalization of the available domestic and authentic pedagogical literature on this issue are given. The shortcomings of the existing definitions of "edutainment" are identified.

The authors of the article understand edutainment as an exclusive educational technology, considered as a combination of modern technical and didactic teaching tools, which is based on the concept of learning through entertainment. The main difference between edutainment and the modern paradigm of learning is that the subject takes an active part in the educational process. The result of the interaction of an informatively entertaining object and an active subject in learning is knowledge, skills, individual experience, and subjective emotions.

Assignments in the technology of "edutainment" should correspond to three pedagogical principles: the connection of theory with practice, consistency, and accessibility. The article proves that edutainment can be attributed to innovative educational technologies.
\end{abstract}

Keywords: edutainment, didactic and technical aids, game technologies, personal motivation, professional competencies, media literacy, developing cooperation, educational environment of the university.

\section{INTRODUCTION}

To date, the educational services market is one of the most mobiles and dynamically developing. Didactic processes are activated, and the demand for creative professional skills is growing. The goals of education are changing, the training of competitive specialists is required, and the priorities in training are changing, in which it is necessary to beat difficult professional situations - and, as a result, there is a need to introduce new game methods and technologies into the educational process of professional education.

The relevance of the study lies in the fact that at present, the social order for higher education is significantly 
focused on the formation of a foreign language communicative competence and the development of communicative skills of oral communication of a university graduate, allowing a future specialist to carry out effective speech communication in a foreign language in professional and general cultural fields. Given the limited time resources allocated to the discipline of a foreign language at a university, there is a need to improve the methodology of teaching a foreign language and use effective technologies in the educational process to meet the requirements of federal state educational standards of higher education.

The purpose of the article is to consider the concept of "edutainment" in the system of general and higher education as an effective technology for the development of the individual's creative potential.

Modern education requires the development of new educational technologies that take into account the latest technical achievements. The use of computers, the Internet, social networks, and multimedia as learning tools will activate cognitive processes, which in turn will contribute to the formation of sustainable educational motivation - "the driving engine that guides students to constructive mastery of knowledge, skills, and abilities. It is the sustainable motivation that determines the high efficiency of the educational process" [Tolmacheva, 2015]. In domestic and foreign pedagogy, the interest in innovative teaching technologies, based on the use of modern teaching aids, (computer, multimedia, video, and alike), is growing. From the psychology of education, such educational technologies contribute to a more effective "digestion" of educational material, which is achieved through students' further inclusion in the educational process. The development of modern society is inextricably linked with the growth of new information. The difficulty lies in the fact that it quickly becomes obsolete, losing its relevance. Thus, it is becoming increasingly difficult to obtain useful and interesting knowledge. That is why the role of the Internet in the learning process is growing. These technical means turn the learning process into useful entertainment. All of the above has led to the emergence of such a learning technology as "Edutainment," which is based on the concept of "education + entertainment."

The purpose of the article is to analyze domestic and foreign studies on the technology of "Edutainment," as well as develop recommendations that allow using this technology in classes of foreign languages.

Game and engaging learning are of particular relevance because, unlike the older generation, modern students prefer other methods of obtaining information. The constant use of computer technology affects their cognitive skills. Young people cope more easily with multi-tasking. They began to understand the information better, presented non-linearly, that is, allowing the active participation of the person who perceives it. The habit of participating in the cognitive process develops the ability to learn from our mistakes. There is an opinion that the technology of "edutainment" meets the needs of a modern person, whose perception is changed due to the constant use of computer technology.

The scientific novelty of the study lies in the fact that the authors have given a scientifically sound definition of the concepts of "edutainment", revealed the specifics of the technology of edutainment in the context of teaching foreign languages. The totality of functional, motivational, organizational and substantive pedagogical conditions is determined, which ensure the implementation of the teaching methodology for students' command in speaking foreign languages based on the technology of edutainment; The effectiveness of the teaching methodology of foreign languages to undergraduate students based on the technology of edutainment is shown. The possibility of integrating the technology of edutainment in the teaching methodology of foreign languages is considered.

\subsection{Current State of Research in the Area under Study (Methodology)}

The term edutainment was first used by The Walt Disney Company, which applied it to its True Adventures series. However, the technology itself was not new. During World War II, the animated series "Private Snafu" was released in the United States, in which viewers were informed of the necessary security measures in time of war thanks to the main character, a soldier, in various situations. In 1973, Robert Hayman first used the concept of "edutainment" in a report for the National Geographic Society. In the 1970s, the principles of the new technology were transferred to the healthcare field in the United States and Great Britain. Through exciting and visual plots, analytical work was carried out among the population on the dangers of drugs, the devastating consequences of AIDS and cancer, and alike. Subsequently, the idea of educational and entertainment programs for children became more popular. Examples of this were Sesame Street, Teletubbies. In Russia, the projects of this kind have also been popular: "ABVGDeyka" and "Good night, kids." These programs have become an example of the introduction of gaming pedagogical technologies in children's entertainment programs. The Experimentanium Museum of Entertaining Sciences has been opened in Moscow, organized on the principle of an entertainment and educational centre in which everyone (adults and children) can learn complex chemical and physical laws in the entertainment area, carry out various experiments (even independently), see shows and attend workshops. 
The definitions of edutainment in domestic and foreign science are very diverse (O. Bogdanova, $\mathrm{O}$. Dyakonova, M. Addis, Sh. De Vary, J. McKenzie, S. Walldén). There is still no consensus on what constitutes an entertainment element in edutainment and what place it should occupy in education. In foreign scientific and pedagogical literature, special attention is paid to the study of pedagogical features of "edutainment." Almost all foreign researchers recognize the creation of an entertaining and educational environment that contributes to the maximum realization of all the possibilities of modern education as a characteristic feature of the edutainment.

In domestic science, the term edutainment has not yet received a broad interpretation. A. Popov defines edutainment as playing - "conveying one important idea, creating dynamic stereotypes, precedents that allow students to take actions automatically in a situation of real choice." Such technology serves to consolidate knowledge and develop specific skills, which becomes more effective in the conditions of using modern technologies. Speaking generally about the game, A. Popov notes that soon, the game will change its primary function (entertainment) to a communicative one. (Popov, 2006). Confirming this idea, he dispels myths about the possibility of attracting a small audience into the game, the limited age of the player, the incompatibility of the game with serious work. O. Gnatyuk defines "edutainment" as "digital content that combines educational and entertaining elements" and at the same time, provides information to the audience with "the most facilitated analysis of events" [Gnatyuk, 2010]. Computer and multimedia have become an integral part of society: therefore, it is necessary to make maximum use of their educational opportunities, which form digital content. The researcher believes that digital content cannot be equated with entertainment: working with pedagogically thought-out assignments will never be easy. M. Zinovkina speaks of "creative education" - "a consistent, purposeful development of the student's methodologies and experience of creative activity transferred to him, with the formation of his own creative experience on this basis." [Zinovkina, 2007]. Education with the use of new approaches contributes to the formation of a creative personality, strengthens the motivation for learning. I. Feklistov offers the term "non-formal education." In his opinion, training is not limited to the pedagogical process. People also develop thanks to their environment, life experience. However, the researcher does not use terms related to entertainment content as part of the learning process, which does not correspond to the English concept of "edutainment": "education" + "entertainment."

The concept of non-formal learning is currently supported by UNESCO: recommendations are being developed for decision-making at the state level, research is being carried out, and analytical reviews are being prepared; monitoring and evaluation services are being created. Note that when using the modern capabilities of computer and game learning, the student acquires new knowledge, enriches his experience, living some life situations. Of particular interest is the study of O. Dyakonova and O. Zheleznyakova. In their view, edutainment is "a particular type of training that begins with entertainment in training, is accompanied by the formation of attraction of students' attention to the subject and, as a result, ends with hobby and pleasure from training [Dyakonova, Zheleznyakova, 2013]. Thus, the student, having an exciting time while mastering some material, draws attention to the features of the subject and remembers its fundamental principles, which leads to the formation of a steady interest, harmoniously combined with the quality of obtaining of knowledge.

In the Russian language, the words "hobby," "attraction" and "entertainment," even though they have the same root, have completely different meanings, due to the presence of different affixes. Based on the S. Ozhegov explanatory dictionary of the Russian language, the authors studied each of these definitions and got the following. Entertainment is a definite "pleasure activity." However, this is only a "one-time attraction" to something. The attraction is characterized by duration. The attraction is "the emergence of interest" or "positive attitude" to something that encourages further activities. Passion is "great steady interest" in something, accompanied by "full dedication." Therefore, a hobby is no longer just an interest in an activity: it is a complete immersion in this activity, accompanied by positive emotions. [Ozhegov, Shvedov, 2001]. Thus, speaking further about "edutainment," it is worth paying special attention to the internal content of the concept since entertainment in learning is only the first stage of enthusiasm for the educational process, accompanied by positive emotions and contributing to the effective "digestion" of the material.

Edutainment, as one of the modern educational technologies, is presented in the research of $\mathrm{N}$. Kobzeva. The author draws attention to the organization of the learning process in comfortable conditions, which, of course, affects the effectiveness of learning. The use of technology guarantees the achievement of results through the integrated use of didactic, technological means of training, and monitoring tools. The researcher gives the following definition: "Edutainment is a learning technology, considered as a combination of modern technical and didactic teaching tools, which is based on the concept of learning through entertainment" [Kobzeva, 2012]. The critical tool of edutainment technology is a game that is organized both with and without a technical training tool. Speech and language games set the creation of a made-up communicative 
situation in which the student is immersed, as their goal. "Living" the situation contributes to the consolidation and activation of the previously studied material. If the traditional game tasks are supplemented by a computer or multimedia (sound, image, visualization), then we will get a widespread impact on the student, which will lead to an improvement in the level of educational material. D. Perushev notes that edutainment is "a technology for transferring knowledge, the ability to learn something new from reliable sources, and not an alternative to academic education: it works in any age group and is not prone to fashion. Depending on the specific event, either the entertaining or educational part may outweigh, the main thing is to have this "mix" [Perushev]. S. Kuvshinov states: "Now a new term has appeared - edutainment ... The educational process is turning into an event, active participation, a kind of action for the student"... the educational process should be an event, a media theatre, and of more than one actor (teacher): everyone participates in this performance" [Kuvshinov]. The following features of the technology of edutainment are distinguished in the scientific and methodological literature: the presence of interactive teaching methods, the presence of a process of two-way interconnected activity of subjects of the educational process (subject-subject relations), the definition of goals in organizing the learning process, creating comfortable conditions, guaranteeing the achievement of a specific result, the integrated use of didactic, technological means of training and control [Kobzeva, 2012].

All the above terms and concepts describe innovative learning, which is very different from the traditional educational paradigm. Thus, the first part of the concept of "edutainment" is undoubtedly revealed, while the second part of this concept by different authors is understood differently: this is a game, a digital content, creativity, and living in the situations asked. Accordingly, in order to resolve the existing contradictions, it is advisable to refer to the primary sources and analyze authentic scientific literature. Yang Wang defines "edutainment" as a "place" where children can enjoy what they learn through sounds, videos, texts, and images [Wang, 2007]. Y. Wang, using the word "place," points to the unique role assigned to entertainment in educational activities. The author believes that the primary goal of "edutainment" is that it helps to diversify the process of obtaining knowledge by entertainment, that is, the theory is mixed with educational goals and means, life values and makes it possible to "present experience and entertainment through creation. However, it is worth noting that, according to the author, "edutainment" covers only a small part of the educational process, it only helps to diversify learning, without requiring the transformation of the traditional learning model. M. Addis believes that "education" is a specific activity based on "simultaneous training and the satisfaction of one's curiosity." Learning or obtaining information is the result of the interaction between the subject (student) and the object (product, event, thought, personality). "Edutainment" differs from the traditional teaching scheme in that, in this case, the subject takes an active part in obtaining information, expresses personal preferences characterized by a subjective reaction. The object, in turn, is not static. It is in motion, transmitting to the student partially information, and partially - entertaining content [Addis, 2002]. P. Donovan refers to "edutainment" as a pedagogical strategy, based on the deliberate "combination of social order with an entertainment mechanism" to quickly achieve individual goals set by the society (Donovan, 2010). The author believes that "edutainment" is sufficient for obtaining more information by a large number of people in a short period, and the presentation of potentially scary topics frivolously takes place.

Thus, "edutainment" acts as the dominant activity, covering a long time and contributing to the achievement of complex goals with the efficient use of available resources, which, undoubtedly, require the transformation of the traditional learning model. Edutainment incorporates the best from related fields of knowledge, such as pedagogy, psychology, computer science, and alike, which $\mathrm{H}$. Hanafizan emphasizes. The researcher believes that in order to ease the learning difficulties for the student, it is necessary to motivate him and try to take into account emerging psychological needs: for this, the teacher should be an expert in his field, masterfully know modern technologies in teaching and involve non-traditional teaching aids, for example, such as a game, relying on a positive personal experience - living certain life situations [Hanafizan, 2003].

In almost any situation, any process or mechanism can be modelled for educational purposes. Involving students in an environment that imitates an area of expertise which is attractive to them is one of the main benefits of edutainment. The authors also set as their goal to test the effectiveness of the proposed methodology of teaching foreign language communication for students based on educational technology in the process of experimental training. To be able to solve the problems and test the hypothesis, the following research methods e able were used:

- Theoretical: analysis of theoretical research and practical work in the field of pedagogy, psychology, teaching methods of foreign languages by both domestic and foreign authors on the topic of research; empirical: questioning, interviewing, conversation, survey, pedagogical observation, testing, content analysis of student work, experimental training; statistical: mathematical processing of the obtained results in the process of a training experiment. The following approaches to teaching a foreign language served as the 
methodological basis of the study: cognitive, competence: communicative, and system. The experimental base was the Law Institute of RUDN University. A total number of 50 students of the third and fourth courses took part in experimental training in practical classes on the discipline of "Foreign language in the field of jurisprudence."

\section{DISCUSSION AND RESULTS}

Even though the primary goal of edutainment is learning, complex topics cannot be learned quickly and easily. In such cases, edutainment does not have to be fun, but it can remain interesting. "... one of the main tasks of edutainment is to provide pleasure to the recipient in the learning process, which can be expressed, for example, through interesting content of the proposed material; satisfaction from the solution of a problem; social interaction with other students; learning progress; motivating, meaningful material for the student, related to the practical aspect of his/her life" [Khangeldieva, c. 207]. As a feature of edutainment technology is the introduction of modern forms of entertainment in the system of traditional lectures, lessons, classes, seminars and masterclasses, since without television programs, desktop, computer and video games, films, music, websites, multimedia programs, and alike it is no longer possible to imagine modern learning and communication.

Workshops and events in the format of edutainment can be held in a cafe, park, museum, office, gallery, club, where one can get information on any cognitive topic in a relaxed atmosphere [Dyakonova, 2015]. Educational means for edutainment can be divided into traditional and modern. Traditional media include books or comics, music, films, educational games, television programs, radio programs, and free lectures. Modern tools of edutainment are divided into electronic systems (electronic textbooks, network versions of museum exhibitions), personal computer systems (computer or video games, electronic simulators, electronic encyclopedias), and web technologies (e-mail, WebQuests, wikis, blogs, chats, video conferences). In European and American schools, free classes, or "classes with open space," are popular. During free classes, the teacher and students are engaged in a dialogue that requires a lot of student activity. The teacher can make lists of topics and give them to a class divided into groups. Pupils can join any group and participate in dialogues, and at the end of the lesson, conclusions are drawn based on what was said [Edutainment or Entertainment, 2007].

Case studies are a learning method based on the consideration of real or made-up situations. This method allows applying theoretical knowledge to solving practical problems. The case study method is most effective at the final stage of the topic. Students receive a folder (case) with information material on the topic. Based on these materials, students put forward a problem and propose a solution to it, analyzing and processing the information. Since it is understood that the problem does not have a single solution, students should substantiate their point of view using their communication and discussion skills.

A web quest is a research-oriented activity in which all or part of the information for a student is taken from the Internet. There are at least two types of web quests. The educational goal of a short-term web quest is to gather information and gain knowledge. At the end of a short-term web quest, a student will process a large amount of information and make sense out of it. A short-term web quest is completed in one to three lessons. The educational goal of a long-term web quest is to expand and improve knowledge. After completing a long-term web quest, the student will analyze a large amount of information, change it, and demonstrate it in such a way that others can comment on it online or offline. A long-term web quest lasts from a week to a month. In order to achieve clarity of the goal for the student and the effectiveness of completing the web quest, the web quest must contain: 1) an introduction, in which the deadline is set, and background information is given; 2) a doable and interesting task; 3) a set of sources of information needed to complete the task. Internet resources are combined in a WebQuest document as pointers to information on the Internet. Sources of information can be web documents, postal addresses of specialists, search databases, books, and other documents available to the student; 4) a description of the process of completing the task.

The process should be divided into logical and detailed steps; 5) guidance on the organization of the information obtained. It may take the form of leading questions or guidance on organizational conditions, such as timelines or conceptual maps; 6) the conclusion, which gives completeness to the quest, reminds students what they have learned, and possibly motivates them to continue research in other areas. Web quests are a group activity, but they can be carried out alone, for example, with distance education or in the library. Web quests can be enhanced by motivational elements, such as game roles (scientist, detective, reporter), which encourage participants in the quest to communicate with each other, and a scenario within which to work. N. A. Kobzeva identifies the following features of edutainment: the presence of a process of bilateral interconnected activity of the subjects of the educational process (subject-subject communication); the presence of goals in the organization of the learning process; availability of comfortable conditions; 
guarantee of achievement of a specific result; complex application of didactic, technological training and control tools. (Kobzeva, 2012).

The task on the technology of "edutainment" should correspond to three pedagogical principles: the connection of theory with practice, consistency, and accessibility. To achieve the principle of the connection between theory and practice, it is recommended to study practice-oriented oral topics, ensure dialogue of communication, including extracurricular activities, perform work using literature in a foreign language, organize the analysis of not only general professional but also communicative competence of students. Search and research tasks are an effective means of linking theory with practice. Theoretical problems can be supplemented by examples from reality. The principle of consistency requires to bring knowledge to the level of consistency, so one should revise the material studied, and study new topics based on that.

The principle of accessibility assumes that the complexity of the tasks corresponds to the age, skills, and abilities of students. The presentation of the material should go from simple to more complex. In edutainment, the principle of constructivism is widely used, according to which the student obtains knowledge from an already known material. The student's knowledge, his experience, ways of solving problems, and understanding of the situation are how the student imagines the world. Learning modifies, realigns, and complements this material. Constructivism attaches new importance in testing a changed view of the subject of education. A necessary prerequisite is the understanding or misunderstanding of the topics for students to study; therefore, self-assessment and reflection are essential skills. If the student does not realize why it is necessary to remember or learn something, the transition of the learning outcome into real life may not occur: the student will not be able to put it into practice in solving problems. Edutainment has excellent potential in eliminating the unequal distribution of information that arose as a result of the uneven development of information technology both around the world and within one country. Edutainment tools may be available and equally understandable for different segments of the population. As cognitive knowledge and media literacy increase, trainees with a low level of knowledge can move on to learning in a more advanced audience.

At the Law Institute of RUDN University, the authors conducted experimental classes using the "Edutainment" technology in foreign language lessons with the third and fourth-year students. Two teams of students were supposed to, in 45 minutes after listening to a video about current events in Catalonia, draw up a model for interviewing participants with journalists, give an assessment of expert lawyers, and express opinions of representatives of international institutions. Further, the assignment was expanded: students drew up historical references, searched for relevant articles of the legislation that made it possible to argue a particular position, which allowed them to master a significant layer of language material, and prepared thematic language presentations. This technology allowed achieving several results at once: changing the type of communication in the lesson (from vertical "teacher-student" to horizontal "teacher-student-student," which helped students get rid of internal fears and complexes). With this kind of work in the audience, the authors note the dominance of a communicative approach, the formation of personal and professional qualities (tolerance, communicativeness, the ability to overcome the psychological barrier in foreign language communication).

The great advantage of this experiment was the fact that communication, training, and the development of professional skills were based on trilingual communication, as students participating in the program "translator in the field of jurisprudence" in the programs of Spanish and English took part in the experiment. Thus, it became possible to exchange and search for information from multilingual sources, introducing the role of a translator in the implementation of interviews, translating without the participation of the Russian language as an intermediary language, namely working in the English-Spanish language pair.

In such an experiment, the main characteristics of the technology under consideration were the informal and positive atmosphere in the classroom, the absence of strict limits and prohibitions, the lack of strict control from the teacher, the unpredictability of the final result, taking into account the individual pace of work, the possibility of active communication and mutual enrichment of knowledge. The authors consider that it possible to characterize the applied experimental technique as developing cooperation, because such methodological tasks seem to be challenging to perform on an individual basis, and this is why cooperation is needed, uniting students with the distribution of their roles in the group, individual and collective goal setting, collective work planning, independent selection of information, and alike. It also allows developing the skills of cooperation and interpersonal communication: the ability to listen, develop a common opinion, resolve disagreements, which will be especially useful for future specialists in the field of a wide area of legal specialities.

We believe that when implementing such educational projects, the following tasks should be used, the list of which, of course, remains open: tasks with the skill of cooperation; with communication skills; with the skill of 
self-representation; tasks aimed at the formation of reflection; tasks with value-semantic settings; tasks aimed at the formation of ICT competencies.

The essence of these tasks, in our opinion, does not lie in the formation of academic knowledge of students, but of professional competencies that allow them to creatively solve tasks and generate new ideas to achieve their results. In this case, the teacher acts as a tutor and motivator whose activity is aimed at developing abilities and motivation to independently find the necessary information, research, analyze, and create.

\section{CONCLUSION}

Despite some disagreements in the works of domestic and foreign researchers, the main feature of the "edutainment" technology is its educational and entertaining nature, the active involvement of modern computer and multimedia teaching aids. Thus, almost all researchers of the "edutainment" technology consider it to be a modern, effective technology, which is able not only to diversify the educational process but also to improve the assimilation of knowledge qualitatively. Consequently, a combination of traditional and innovative teaching methods can diversify teaching material, increase students' interest in classes, and also develop their communicative activity and intrinsic motivation.

After analyzing the definitions given by foreign authors, we concluded that, despite the different verbal design, they all see the concept of "edutainment" in almost the same way - this is training and entertainment. "Edutainment" is a modern pedagogical innovation, which is based on visual material, narration, modern psychological techniques, a game format, modern information and communication technologies, more informative and less didactic teaching methods, the purpose of which is to facilitate the analysis of events, maintaining an emotional connection with the object of training, the attraction and long-term retention of the attention of students. It turns out that the primary goal of edutainment is to transfer knowledge, attitudes, experience, or skills.

However, for the successful transfer, receipt, and assimilation of information, it is necessary: 1) to encourage students to pay attention to the phenomenon being studied, to arouse their interest, to encourage active participation in the process of acquiring knowledge; 2) during the process of acquiring knowledge, it is necessary to give students pleasure, fully engage them and distract them from outside thoughts or experiences; 3) and ultimately, having greatly interested students, make them completely surrender to the lesson or idea. Therefore, "edutainment" is not just training and entertainment; it is attraction, training, entertainment, and enthusiasm with the help of various teaching aids and taking into account the specific psychological needs of students.

The feature of technology of edutainment in pedagogy and methodology includes:

validity (training is more successful when students can see the usefulness of the knowledge gained); additional training (training is more effective when students can acquire knowledge on their own); distributed learning (a network of distributed learning that provides full access to the educational resources of many users, in which all students learn differently and at different periods).

The specificity of this learning technology is determined by the presence of the following features:

Focus on enthusiasm: the student's immediate interest is essential, which leads to the development of new skills and the accumulation of knowledge.

Emphasis on entertainment: it is entertainment that acts as the primary motive that leads to pleasure, while at the same time forming a keen interest in the learning process, removes the psychological burden from the educational process.

Game approach: thanks to the versatility of the game, the effective learning process takes place regardless of age.

Focus on the present: when using the relevant capabilities of modern technologies, such as video and audio materials, didactic games, educational programs in a multimedia format, and many other means, the maximum involvement of students in the educational process is achieved.

Despite its popularity, the technology of "edutainment" needs to be significantly improved. An important issue is the balance between learning and entertainment. Tasks created to increase interest should be reasonably combined with tasks to increase intelligence.

With all the variety of educational innovations offered by the edutainment, the main advantage of the method is the rehabilitation of unconscious learning mechanisms, which explains such a high degree of demand for the discussed technology, among other didactic innovations. 
The results of the study can be adapted for teaching students of various professional areas of training in teaching any foreign language used in the development of original courses and continued training in foreign languages.

\section{ACKNOWLEDGEMENT}

This article has been prepared in the framework of RUDN University participation of Russia-wide 5-100 program.

\section{REFERENCE LIST}

Bogdanova, O., (2014). Edutainment as a special type of teaching. Vestnik MGPU. Vol. 4 (30). pp. 61-65.

Dyakonova, O. (2012). The concept of "edutainment" in foreign and domestic pedagogy. Siberian Pedagogical Journal. No 6. pp. 182-185.

Gnatyuk, O. (2010). Fundamentals of the theory of communication. Moscow, KNORUS, $256 \mathrm{p}$.

Zheleznyakova, O., Dyakonova, O. (2013). The essence and content of the concept of "edutainment" in domestic and foreign pedagogical science. Retrieved from URL: http://www.almavest.ru/en/favorite/2013/05/14/387/

Zinovkina, M. (2007) Pedagogical creativity. Modular-coded textbook. Moscow, MGIU, 258p.

Kobzeva, N. (2012). Edutainment as a modern technology of education. Yaroslavl Pedagogical Bulletin, No. 4 (II) (Psychological and Pedagogical Sciences): pp.192 - 195.

Kuvshinov, S. Edutainment: Audio-visual interactive technology in education. Retrieved from URL: http://www.polymedia.ru/ru/news/142/

Ozhegov, S., Shvedova, N. (2001). Explanatory dictionary of the Russian language. Retrieved from URL: http://www.ozhegov.org.

Perushev, D. Lessons of word formation. Retrieved from URL: http://exam-ans.ru/voennoe/3752/index.html.

Popov, A. (2006). Marketing games. Entertain and conquer. Moscow, Mann, Ivanov, Ferber, 320p.

Tolmacheva, E. (2015). Innovative training of RaF ("Construction Management") based on information and communicative WebQuest technology. Abstract of dissertation of thesis. Moscow, 2015, 26p

Feklistov, I. (2002). A manual on human rights education with youth. Moscow, Council of Europe, 478p.

Addis Michela. (2002). New technologies and cultural consumption. Edutainment is born. - Bocconi: Bocconi University. Marketing Department, pp. 1-13.

Donovan Rob, (2010). Henley Nadine Principles and Practice of Social Marketing, an International Perspective. Cambridge: Cambridge University Press, p. 504.

Hanafizan, Hussain (2003). A Conceptual Framework for Edutainment. Informing Science. Vol. 6, pp. 10771083.

Wang, Yan. (2007). Edutainment technology - a new starting point for the education development of China. Section T1B-5, 37th ASEE/IEEE Frontiers in Education Conference, October. - Milwaukee: WI, pp. $10-13$.

De Vary Sh. (2008). Educational Gaming. Interactive Edutainment. Distance learning. Boston, Information Age Publishing. No.5. pp. 35-44.

McKenzie, J. (1999). Beyond Edutainment And Technotainment. From Now On, Retrieved from URL: http://fno.org/apr99/covapr.html

Walldén, S. (2004). Edutainment from Television and Computers to Digital Television. University of Tampere Hypermedia Laboratory, Retrieved from URL: http://www.uta.fi /hyper/julkaisut/b/fi tv03b.pdf

Khangeldieva, I. (2013). Edutainment: from the television format to modern social and educational practices. Ed. by Khangeldieva I. G., Bogdanova E. M. Proceedings based on All-Russian scientific conference materials "Culture and education in modern society: development and conservation strategies." Krasnodar: Ecoinvest LLC. pp. 206-218. 
Dyakonova, O. (2015). Didactic utilitarianism: edutainment as an innovative solution to adult education problems. Tomsk State University Journal. Tver state university. No. 3. pp. 271-276.

Edutainment or Entertainment. (2007). Education Possibilities of Didactic Games in Science Education / The Evolution Of Children Play - 24. ICCP Word Play Conference. Brno: Pedagogická fakulta, Masarykova univerzita, Brno, Retrieved from URL: http://www.iccpplay.org/documents/brno/\%20nemec trna.pdf 